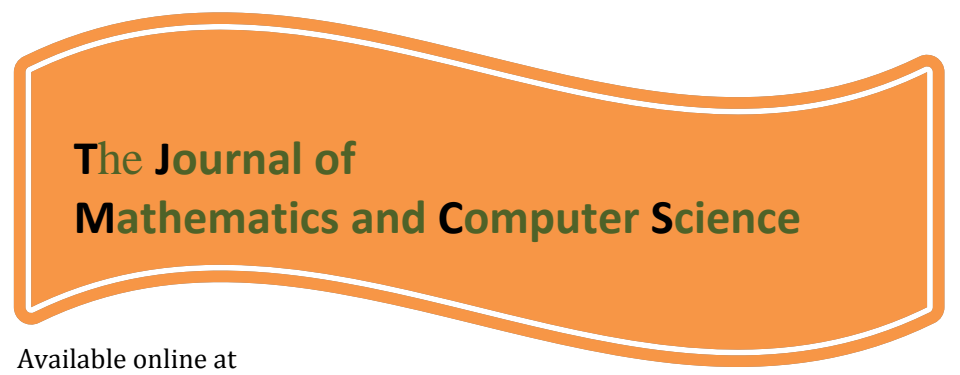

http://www.TJMCS.com

The Journal of Mathematics and Computer Science Vol .2 No.2 (2011) 319-328

\title{
The study of Guilan university students in math lesson (amount of math Skill) in different recognition compasses
}

\author{
Ahmad hedayat panah \\ Mo'in technical vocational school Rasht Iran \\ Education Complex payambare a'azam \\ A_hedayatpanah@yahoo.com
}

Received: September 2010, Revised: December 2010

Online Publication: January 2011

\begin{abstract}
$\underline{\text { Abstract }}$
Math teachers often make math exam quetions in a practical way and they don't focus on meanings and skills a lot.

While the usage of six recognition compassen can help the measurement of learning levels and skills a lot. so, this research has the aim of studying Guilan University student's skills in math lesson according to Bloom's recognition compasses. Statistical samples were 241 university students (males and females) from different branches of technical major who answered math questions from whatever they had learned before entering the university (high school and arts - and - crafts school).The Exam included 50 multiple choice questions which were designed and classified due to Benjamin Bloom's recognition compasses, the questions were given to university students to be answere in a determined time limit. Results show that:

a) Students had the best performance in science, understanding (perception) and application (somehow in low compasses), but they had the least performance in evaluation and judgement, analysis and combination (somehow in high compasses).

b) Girls had the most performance in understanding (perception) and application compasses but in other compasses, boys had better performance.

c) In none of the recognition compasses, students had a performance of more than $50 \%$, or we can say that in none of recognition compasses, they could answer more than $50 \%$ of the qnestions.
\end{abstract}

Key words: recognition compass, math skill, Guilan university student, Bloom

\section{Introduction}


The taxonomy of teaching purposes in different learning compasses, from Benjamin Bloom's point of view is classified into $\underline{\underline{3}}$ categories including: recognition, emotional, and psychic and dynamic compasses which are like an en bloc channel. It means that learning and teaching purposes in psychic and dynamic compass is mixed with learning in recognition and emotional compasses and also they can't be separated.

Some actions are more likely to be a recognition action rather than a dynamic one, and some of them have a stronger emotion part, other groups which are recognized by their more recognizable scientific skills are classified into dynamic emotional compass.

For example, each proper teacher tries to make an interest in his or her students (emotional aim) so that they learn the lessons (recognition aim). In other cases, a teacher tries to change the tendency (emotional aim) with having knowledge and information (recognition aim) but dynamic emotional skills require the cooperation of nerve and muscles for example tailoring, driving, scientific skills in technical fields, sports, art, lab works and works like these.

Becauos of the expansion of domine, due to Dave theory (1969), there is a cooperation between emotional and dynamic actions which are performed by different parts of body. Dave taxonomy starts with simple act of seeing and mimicking and little by little reaches higher levels like acting without any help, precision in actions, unision in movements and ends in simplifying the action. Generally there is no agreement on different levels of learning. Gilford (1968), kibler and Baker Maltz (1970), and Harn (1972) had some theories in this prespective.

In this paper, the purpose of recognition compass, depending on dynamic emotional compass emphasizes on recalling or rebuilding the things the learning of which is necessary. Purposes are adjusted from the simplest levels of recognition to the most complicated ones and from natural and sensible actions to spiritual and non - sensible ones. According to Bloom's classifications, learning purposes in recognition compasses include six levels:

\section{Knowledge}

Learning at this level means gaining knowledge and only includes the memorization aspect.

\section{Understanding}

Learning at this level includes the ability of understanding the meaning of a subject and clarifying it with the sentences that the person himself makes without making any rclation between that subject and The other subjects.

\section{Application}

Learning at this level includes the ability of using scientific principles, hypothesis, and other abstract coneepts in suitable situations without presenting any solution.

\section{$\underline{\text { Analysis }}$}

Learning at this level requires the ability of analyzing the subject and breaking it down to its fundamental parts and determining the relation between different parts and also understanding that how different parts are gathered together and also the purpose of whole system.

\section{Composition}

At this level, the learnes can make a new meaning with the materials that he gained from last part.

\section{Evaluation and judgement}

This level includes judging about subjects, information and even ways of facing the questions and problems. At this level diciding is inevitable for learner. 
Ahmad hedayat panah/ TJMCS Vol .2 No.2 (2011) 319-328

Mathematical skills and focusing on meanings are not usually taken seriously by the teachers. Most of the teachers in designing mathematics exams, usually choose useful and classic exercises and they don't notice the skill - learning and learning levels. Whereas measuring learning levels and mathematical skills, depending on reognition compasses, can be so helpful and effective. This research deals with the study of performance and determining the amount of university student's skills.

As one can see, the simplest recognition starts with remembering and ends in the most complicated way called evaluation and judgement. Most of the times,The aim is the simplest purpose of learning which are gaining knowledge and remembering, and also measuring educational advancements are based on this compass. The writer measured mathematics lesson of Guilan University students due to the things they had learned before entering university (high school and arts - and - crafts school) to delineate their learning levels and skills in different compasses, and also to recognize the mistakes and problems. So the main question in the research is:"what's the status of mathematics lesson for university students in lerning compasses (recognition and skill) due to their gender (male or female)? What's the relation between girl's and boy's mathematics status due to Bloom's different recognition compasses?

\section{Researeh Purposes}

\section{Main purpose}

The study of Guilan technical university student's mathematic status depending on recognition compasses.

\section{Side purpose}

The study of Guilan technical university student's mathematics status depending on recognition compasses consedering thier gender.

\section{Statistical samples}

Statistical samples were 241 university students (166 boys and 85 girls) from 10 different classes of Guilan technical university. Statistical model included 4 classes of Dr. Moeen girl's college (Rasht), 3 classes of shahied chamran college (Rasht) and 3 classes in shahid khodadadi college (Anzali).

\section{Research Method}

The researeh method is descriptive and it's of surveying type.

\section{Research Tools}

TwoQuestionnaires were made by researcher including 10 questions about personal characteristies of the person who was being interviewed and 50 mathematic multiple choice questions in different recognition compasses. 10 questions in evaluation and judgement compass and the rest of them in other compasses (8 qnestions for each compass), each question has 1 point. Questions were designed from high school and art mathematical books (courses which they learned before university). Some questions had more than one correet answer so their answering power could be measured better and the chance for answering the questions chance would be minimized. The students were also asked to answer 2 of questions in a deseriptive way but only $2 \%$ of the students did that.

\section{Validity}

To design those questions that researcher needed to reduce their mistake rate and also to make clear all the expressions and meanings which were used in questions, the researcher needed to consult with some experts and professionals in designing questions and they also consulted with some mathematic experts for designing questions. Exam was tested on some other students before they take the exam from original students.

Model - finding and data - collecting method: 
Ahmad hedayat panah/ TJMCS Vol .2 No.2 (2011) 319-328

Methods used to find models were cluster multiple steps and random one.The Researcher himself went to different classes and gave the questionnairs to students to complete them within a time limit.The time was equal for all the students.

\section{Statistical methods}

The Researeher used factors such as median, percentage, diagrams, affluence dispense tables to analyze the data and also used deduction statistic factors like analysis of variance, T\&F examination, khido (chi Squre) examination.

\section{Discoveries}

$\checkmark$ Sanjesh organization report cards show that $97 / 2 \%$ of students who entered college answered less than $50 \%$ of the questions of enterance exam. ( boys $95 / 3 \%$ and girls $98 \%$ ).

$\checkmark 14 / 5 \%$ of the students claim that average mathematics score in high school or arts - and - crafts school was between 17 and 20 and 28/3\% claim that their average score was between 14 and 17 and $31 / 5 \%$ say that it was between 12 and 14 . Table (1) shows more information.

Table(1)

\begin{tabular}{|l|l|l|l|l|l|l|l|l|}
\hline $\begin{array}{l}\text { farameter } \\
\text { Sample }\end{array}$ & $\begin{array}{l}\text { Frequency } \\
\text { and } \\
\text { present }\end{array}$ & $0-10$ & $10-12$ & $12-14$ & $14-17$ & $17-20$ & $\begin{array}{l}\text { non } \\
\text { question }\end{array}$ & totol \\
\hline \multirow{2}{*}{$\begin{array}{l}\text { Boy } \\
\text { students }\end{array}$} & $\mathrm{f}$ & 5 & 32 & 63 & 41 & 11 & 4 & 156 \\
\cline { 2 - 9 } $\begin{array}{l}\text { Girl } \\
\text { studens }\end{array}$ & $\mathrm{f}$ & $3 / 2$ & $20 / 5$ & $40 / 3$ & $26 / 3$ & $7 / 1$ & $2 / 6$ & 100 \\
\cline { 2 - 9 } Total & $\mathrm{f}$ & $3 / 2$ & $10 / 6$ & $15 / 3$ & $31 / 7$ & $28 / 2$ & $11 / 8$ & 100 \\
\cline { 2 - 9 } & $\%$ & $2 / 9$ & 17 & $31 / 5$ & $28 / 3$ & $14 / 5$ & $5 / 8$ & 100 \\
\hline
\end{tabular}

$\checkmark$ Selected university students answered $37 \%$ of the questions correctly (girls $36 \%$ and boys $37 \%$ ) The median Correet answers is about 18/5 out of 50 (girls 18/09 and boys 18/8)

$\checkmark$ Selected university students chose wrong answers for $40 \%$ of questions (grils $26 \%$ and boys $46 \%$ ). Median for wrong answers is about 20 out of 50 (girls 13/3and boys 23/3). Table (2) shows more details: 
Table(2)

\begin{tabular}{|c|c|c|c|c|c|c|c|}
\hline $\begin{array}{l}\text { parameter } \\
\text { sample } \\
\text { Group }\end{array}$ & $\begin{array}{l}\text { Frequency } \\
\text { and present }\end{array}$ & $\begin{array}{l}\text { C0rrect } \\
\text { answer } \\
\text { (Total) }\end{array}$ & $\begin{array}{l}\text { Wrong } \\
\text { answer } \\
\text { (Total) }\end{array}$ & $\begin{array}{l}\text { Non } \\
\text { answer } \\
\text { (Total) }\end{array}$ & $\begin{array}{l}\text { (Avereg) } \\
\text { correct } \\
\text { answer }\end{array}$ & $\begin{array}{l}\text { (Avereg) } \\
\text { wrong } \\
\text { answer }\end{array}$ & Total \\
\hline \multirow{2}{*}{$\begin{array}{l}\text { Boy } \\
\text { students }\end{array}$} & $\mathrm{f}$ & 2935 & 3643 & 1222 & $18 / 8$ & $23 / 3$ & 7800 \\
\hline & $\%$ & 37 & 46 & 17 & 37 & 46 & 100 \\
\hline \multirow{2}{*}{$\begin{array}{l}\text { Girl } \\
\text { studens }\end{array}$} & $\mathrm{f}$ & 1393 & 1027 & 1430 & $18 / 09$ & $13 / 3$ & 3850 \\
\hline & $\%$ & 36 & 26 & 38 & 38 & 27 & 100 \\
\hline \multirow[t]{2}{*}{ Total } & $\mathrm{f}$ & 4328 & 4670 & 2652 & $18 / 5$ & 20 & 11650 \\
\hline & $\%$ & 37 & 40 & 23 & 37 & 40 & 100 \\
\hline
\end{tabular}

* Mathematies scores status in different recognition compasses.

a. correat answer

b. wrong ansvers

a) Based on the information gained from research, in low compasses like understanding and application, students gained the highest scores. They answered $40 \%$ of questions in seience compass, $44 \%$ in understanding compass, and $47 \%$ in application compass. In recognition compass, they had the lowest performance in the same order mentioned or to make it more clear we can say they answered $25 \%$ in evaluation and Judgement compass, $29 \%$ in combination compass, $39 \%$ in analysis compass. Girls had better performance in application and understanding compasses but in other compasses boys performed better than girls. Table (3) shows the expansion of correct answers for different genders in different compasses.

Table(3)

\begin{tabular}{|c|c|c|c|}
\hline $\begin{array}{l}\text { parameter } \\
\text { Domin }\end{array}$ & females & males & Total \\
\hline knowledge & $\%$ & $\%$ & $\%$ \\
\hline understand & 37 & 42 & 40 \\
\hline appliction & 45 & 43 & 44 \\
\hline analize & 54 & 12 & 39 \\
\hline combination & 32 & 42 & 29 \\
\hline comprehention & 27 & 30 & 25 \\
\hline Total & 22 & 26 & 37 \\
\hline
\end{tabular}

It's obvious from the table that girls had the highest performance in application compass and the lowest performance in evaluation and judgement compass, but boys had the highest performance in understanding compass and the lowest performance in application compass.

b) Based on the information gained from the research, Guilan technical university students chose wrong answers for $40 \%$ of mathematics questions (girls $26 \%$ and boys $46 \%$ ). Most of the wrong answers were related to combination compass with $50 \%$ wrong answers (girls $25 \%$ and boys $62 \%$ ). The least wrong answers were related to evaluation and judgement compass with $32 \%$ wrong answers (girls $20 \%$ and boys $40 \%$ ). Table (4) shows the expansion of wrong answers for different genders in different compasses.

Table (4) 
Ahmad hedayat panah/ TJMCS Vol .2 No.2 (2011) 319-328

\begin{tabular}{|c|c|c|c|}
\hline $\begin{array}{l}\text { Parameter } \\
\text { Domin }\end{array}$ & females & males & Total \\
& Percent (\%) & Percent (\%) & Percent (\%) \\
\hline knowledge & 28 & 50 & 43 \\
\hline understand & 41 & 43 & 42 \\
\hline appliction & 20 & 43 & 35 \\
\hline analize & 26 & 41 & 36 \\
\hline combination & 25 & 62 & 50 \\
\hline comprehention & 20 & 40 & 43 \\
\hline Total & 26 & 46 & 40 \\
\hline
\end{tabular}

From charts ,we can conclude that university Students answered 87 percent of the whole question (marked them, including correct and incorrect answers).But they didn't mark 13\% of questions( in other words , they left questions unanswered). They also answered $83 \%$ of questions related to knowledge prespective( including correct and incorrect) and they didn't mark 17\% of questions( in other words, they left them unanswered).

chart Number(5) shows the explanation of university students answers (correct or incorrect).

Table(5)

\begin{tabular}{|c|c|c|c|}
\hline Domin & $\begin{array}{c}\text { Correct answer } \\
\text { Percent (\%) }\end{array}$ & Wrong answer & Pon answer (whith) \\
& 40 & 43 & Percent (\%) \\
\hline knowledge & 44 & 42 & 17 \\
\hline understand & 47 & 35 & 14 \\
\hline appliction & 39 & 36 & 25 \\
\hline analize & 29 & 50 & 21 \\
\hline combination & 25 & 33 & 45 \\
\hline comprehention & 47 & 40 & 13 \\
\hline Total & & \\
\hline
\end{tabular}

From chart 5 it's clear that students marked the 3 below prespectives (knowledge - perception appliction)more than the others . In other words, the least answered "No answer" and this is the most commen test which is usually distributed amoung then and they have the best skill and power in answering, but they answered the worst in $\underline{3}$ above prespectives (analysis -composition - evaluation and Judgement) i.e.they left them unanswered, and this is the case that isn't usually considered in evaluation.

\section{Discusion and Result}

The acquired results out of this research confirms the results taken by Alamalhoayee(2002), which were collected about learning styles and it's generalization to the prespective, The resuls of this research also agrees with the results collected by

(Jafari, Alamalodayee, 2006). It's better to design the final exam and to evaluated the students performance based on the recognition perspective.

\section{References:}


Ahmad hedayat panah/ TJMCS Vol .2 No.2 (2011) 319-328

1. Allahyari, Sohbatoalla(2001) "to study the high school mathematic training problems at Bijardar town"

2. Alamalhodaei, H (2001) "Convergent/divergent cognitive Styles and mathematics problem solving journal of science and mathematics education in southeast Asia" 24(2).

3. Alamalhodaei, H (2002) "student's cognitive style and mathematical word problem solving ferdowsi, university of mashhad-IRAN"

4. Alamalhodaei,H (2002) " New approach in mathematic training, shive publishing 1 th edition. "

5. Beyer, B, (1998), develops a thinking skills program Boston Allyan Bacon.

6. Brose Joice and Marshavil (2007) " New teaching method, translator, "

Behranghi Mohammad Reza (1997) Guilan published, 5th edition .

7. Case R, and Globe son,T, (1974): "Field independence and central computing space child development 45".

8. Ekbia and Alamalhodaei, H (2000) "A study of the effectiveness of working memory and cognitive styles on mathematics per for mance of (13 year-old) schoolboys unpublished MA desertation Tehran university of teacher training".

9. Eric Jones, Rich Wilson and Shalini (1997) "Journal learning disabilities.

10. Faryar, Akbar and Fereidoon Rakhsan, (1379) earning disabilities, Mabna publishing, "4th edition.

11. Fallah chi, Seyed REZA (2005), "to study the writing and reading disorder among the elementary student M.A thesis in psychology teacher training university. "

12. Ghodrati, Masoome (2000). "to compare cooperative learning effect with individual learning in remembering, comprehension, analyzing and judyment scientific information rate of empirical science student garde 5, Qhom, A.M thesis, curriculum development.

13. Hojjati, Mohamad Bagher (1989) "Islam educational problem. Islam cultural publisher office. "

14. Hassan nejad, Afsane (2001) to study the learning disorder and mathematic comprehension of the grade 1 high school in mathematic lesson- spring Mashhad university".

15. Hedayat panah- Ahmad (2007), " to study the ways to increasing effective compensatory classes and completing mathematics lesson on educational progress- Guilan research councile. "

16. John Best, (1998), "research method in educational and behavioral science, translators, Pasha Sharifi and Narghes Taleghani, Rasad publisher, " 7th edition.

17. John Glaver and Other... (1998) "cognitive psychology for teacher, translator. Ali Naghi Khazazi, 1th edition. "

18. Jorge Poolia, (1998) " how can resolve a problem, translator, Ahmad Aram, Keihan pubisher", 4 th edition.

19. Karimi Yosef(2002) " learning disorders ... savalon publishing, " 1th edition 
Ahmad hedayat panah/ TJMCS Vol .2 No.2 (2011) 319-328

20. Keramati Mohamad Reza (2003), "to study the cooperative learning effect on social development and progressive of student in mathematic lesson of elementary 5 garde, Mashhad city Iran. "

21. Kohen A (1995) puni shed by rewards? Educational leader ship Vole 53, No 1.

22. Kohen E (1994) Restructuring the classroom Review of Educational research 64 (1) word count 0018377 file".

23. Lois Kohen and Misheal Haliday (2002), " statistic in educational sciences and physical education, translator. Ali delavar Allame Tabatabai university publishing, 3th edition Tehran. "

24. Maureen Asmilte and cynthin (1990). " Research on Learning and Learning mathematics. "

25. Miceal icenak, (2000), " descriptive dictionary of cognitive psychology, translated by Alinaghi Kharazi and ... 1th edition. "

26. Negharesh Nejad, Abdo Al Majid (2002), " statical elementary method in educational science, sohfi publisher, " 1 th edition.

27. Parian.j.kerti (1999) " active learning- school publisher- translator, Faroogh Tansaz, "third edition.

28. Patretiawoif, Brain (2004) " learning process, translator, Davood Ablghasemi, first edition.

29. Seif, Ali Akbar (2002), "measurement and training appraisal method, " Doran publishing- $6^{\text {th }}$ edition.

30. Shariatmadari- Ali (1990), "educational psychology Amirkabir publishing institute".

31. Shoarinejad, Ali Akbar (1968), "developmental psychology- information publishing, " 5th edition.

32. Shabani, Hassan (1998), " educational and training skills, samt publishing", 1th edition.

33. Shokahi, Gholamhosein (1985), " learning method for calculating and geometry, shokoohi Pirooz publishing, " third edition.

34. Slavin R, (1987) " coperative learning, the elementary school "journal 88.

35. Slavin, R (1991) "Group- rewards make group work educational leader ship 48".

36. Slavin R, (1992) "when and why deeps cooperative learning increase achivment Cambridge University press. "

\section{Appendix (1)}

Some examples of math questions based on Bloom's Taxonomy

\section{Knowledge Tasks:}

1. Determine which of the following statements is true:

a. Derivative of a function and differential is the same mathematical concept.

b. Derivative is a limit, but differential is not.

c. Differential is a limit, but derivative is not.

d. Derivative is the same as instantaneous velocity.

2. Determine which of the following relations is not true:

e. $\log a / b=\log \mathrm{a}-\log \mathrm{b} \quad$ f. $\log \mathrm{ab}=\log \mathrm{a}+\log \mathrm{b}$ 

g. $\log (a-b)=\log a-\log b$
h. $\log ^{5}=5 \log ^{a}$

\section{Comprehension Tasks:}

1. Consider set $A=\{\varnothing,\{\emptyset\}$, and determine whether each of the following is true or false:
a. $\emptyset \in$
b. $\varnothing \subset A$
c. $\{\varnothing\} \subset A$
d. $\{\{\varnothing\}\} \in A$

2. Determine whether each of the following statements is true or false:

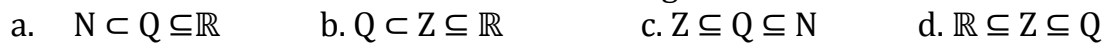

Application Tasks:

1. Determine whether or not each relation below is a function from $\mathbb{R}$ into $\mathbb{R}$ :
a. $\mathrm{Y}=\sqrt{x}$
b. $\mathrm{y}^{2}$
c. $|\mathrm{x}|+|\mathrm{y}|=8$
d. $y=|x|$

2. Suppose $A=\{7,8,9\}$ and $B=\{7,8,11,12\}$, determine whether each of the following statements is true:
a. $\mathrm{A}-\mathrm{B}=\{7,8\}$
b. $A-B=\{9\}$
c. $B-A=\{7,8,11,12\}$
d. $B-A=\{11\}$

\section{Analysis Tasks:}

1.If a, b, c $\in \mathbb{R}$ and $c<d$ which of the following statements is always true:
a. $\quad a b<1$
b. ac $<$ bd
c. ac $>$ bd
d. $a+c<b+d$

2.determine which of the following is always a true statement:
a.tan $x+\cot x=1$
b. $\sin x+\cos x=1$
c. $-1 \leq \tan \leq 1$
d. $\tan ^{2} x+\cot ^{2} x=1$

\section{Synthesis Tasks:}

1. let $A$ and $B$ a matrix, which of the following statements is not true:
a. $\mathrm{A}+\mathrm{B}=\mathrm{B}+\mathrm{A}$
b.A.B = B.A
c. $\mathrm{IA}=\mathrm{AI}=\mathrm{A}$
d. $(A+B)+C=A+(B+C)$

2. Determine which of the relations is true:
a. If $x>0$ then $x^{2}-x>0$
b. If $0<x<1$ then $x^{2}-x>0$
c.If $0<\mathrm{x}<1$ then $\mathrm{x}^{2}<\mathrm{x}$
d. If $x>1$ then $x^{2}-x<0$

\section{Evaluation Tasks:}

Let $\mathrm{S}=\mathrm{Lim} \frac{x^{2}-1}{2 x^{2}+1}$. Determine which of the following is the correct answer :
a. $-1 \quad x \rightarrow \infty$
b. +1
c. $1 / 2$
d. 2

1. Determine whether each of the following is the domain of fraction $g(x)=\frac{x^{2}}{x^{2}+1}$
a. $\quad \mathbb{R}$
b. $\mathbb{R}-\{2\}$
c. $\mathbb{R}-\{-2\}$
d. $\mathbb{R}-\{-1,2\}$ 
Ahmad hedayat panah/ TJMCS Vol .2 No.2 (2011) 319-328

\section{Appendix (2)}

Some position scoring student to solution math

\begin{tabular}{|c|c|c|c|c|c|c|c|c|c|c|c|c|}
\hline \multicolumn{2}{|c|}{$\begin{array}{l}\text { Evaluation and } \\
\text { Judgment }\end{array}$} & \multicolumn{2}{|c|}{ Synthesis } & \multicolumn{2}{|c|}{ Analysis } & \multicolumn{2}{|c|}{ Application } & \multicolumn{2}{|c|}{ Comprehension } & \multicolumn{2}{|c|}{ Knowledge } & \multirow[t]{2}{*}{ Code } \\
\hline $\mathrm{F}_{0}$ & $\mathrm{~T}_{0}$ & $\mathrm{~F}_{0}$ & $\mathrm{~T}_{0}$ & $\mathrm{~F}_{0}$ & $\mathrm{~T}_{0}$ & $\mathrm{~F}_{0}$ & $\mathrm{~T}_{0}$ & $\mathrm{~F}_{0}$ & $\mathrm{~T}_{0}$ & $\overline{F_{0}}$ & $\mathrm{~T}_{0}$ & \\
\hline 3 & 6 & 1 & 2 & - & - & - & 3 & 2 & 1 & - & - & 109 \\
\hline - & 1 & 7 & 1 & 7 & 8 & - & 4 & 4 & - & 7 & - & 166 \\
\hline- & - & - & - & - & - & - & - & - & - & - & - & 284 \\
\hline 1 & 3 & 1 & 1 & 4 & 1 & - & 5 & 1 & 3 & 1 & 2 & 172 \\
\hline 1 & 3 & - & 2 & - & 2 & 3 & 5 & 2 & 3 & - & 1 & 107 \\
\hline 6 & 3 & 7 & 1 & 6 & 2 & 5 & 3 & 7 & 1 & 5 & 3 & 287 \\
\hline 1 & 1 & 2 & 3 & 3 & 2 & 1 & 3 & 3 & 4 & 3 & 2 & 152 \\
\hline- & - & - & 2 & - & 1 & - & 5 & 2 & 5 & 2 & 2 & 160 \\
\hline 1 & 2 & - & - & - & 2 & - & 5 & 3 & 4 & 1 & 1 & 163 \\
\hline 5 & 3 & 3 & 5 & 3 & 5 & 5 & 3 & 8 & 0 & 5 & 3 & 236 \\
\hline- & 6 & 1 & 5 & 5 & 2 & 1 & 7 & 2 & 4 & 4 & 4 & 306 \\
\hline 4 & 5 & 5 & 3 & 5 & 3 & 3 & 5 & 2 & 6 & 4 & 4 & 294 \\
\hline- & 5 & - & 4 & - & 5 & - & 8 & - & 6 & - & 7 & 313 \\
\hline 1 & 5 & 2 & - & - & 2 & - & 5 & - & 2 & - & 2 & 345 \\
\hline 8 & 0 & 7 & 1 & 5 & 3 & 2 & 6 & 6 & 2 & 6 & 2 & 243 \\
\hline 5 & 3 & 6 & 2 & 6 & 2 & 7 & 1 & 7 & 1 & 3 & 5 & 201 \\
\hline 6 & 3 & 7 & 1 & 6 & 2 & 5 & 3 & 3 & 5 & 3 & 5 & 218 \\
\hline 7 & 3 & 5 & 3 & 5 & 3 & 1 & 7 & 4 & 2 & 3 & 4 & 300 \\
\hline 3 & 5 & 3 & 4 & 5 & 3 & 0 & 8 & 4 & 4 & 6 & 2 & 305 \\
\hline 3 & 7 & 2 & 4 & 1 & 5 & 2 & 6 & 5 & 3 & 5 & 3 & 301 \\
\hline 2 & 7 & 4 & 4 & 8 & - & 1 & 6 & 2 & 2 & 2 & 5 & 347 \\
\hline 5 & 5 & 5 & 3 & 5 & 3 & 5 & 3 & 4 & 4 & 4 & 4 & 310 \\
\hline 10 & - & 1 & 3 & 1 & 1 & 1 & 7 & 1 & 3 & 1 & 3 & 351 \\
\hline 19 & 31 & 3 & 5 & 5 & 3 & 1 & 7 & 3 & 5 & 3 & 5 & 324 \\
\hline 0 & 4 & 1 & 2 & 2 & 6 & 1 & 5 & 2 & 5 & 1 & 4 & 346 \\
\hline- & 10 & 8 & - & 3 & 5 & 2 & 6 & 6 & 2 & 4 & 4 & 304 \\
\hline
\end{tabular}

